\title{
Corrigendum: Critical analysis of the role of innovative capabilities on firm performance: Evidence from the University of Cape Coast administration in Ghana
}

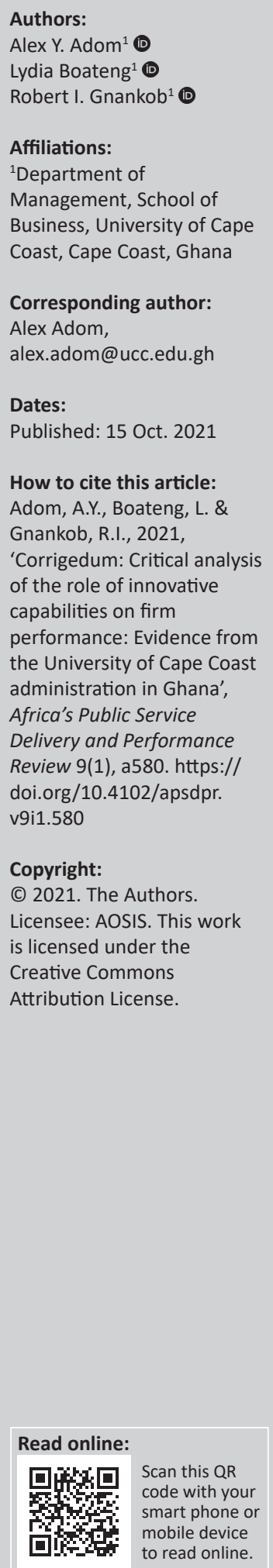

In the version of the article initially published, Adom, A.Y., Boateng, L. \& Gnankob, R., 2019, 'Critical analysis of the role of innovative capabilities on firm performance: Evidence from the University of Cape Coast administration in Ghana', Africa's Public Service Delivery and Performance Review 7(1), a256. https://doi.org/10.4102/apsdpr.v7i1.256, the name of the third author was given incorrectly. The correct name should be Robert I. Gnankob instead of Robert Gnankob in the 'Authors' and 'How to cite this article' sections.

This correction does not alter the study's findings of significance or overall interpretation of the study's results. The authors apologise for any inconvenience caused. 